\section{La Corte Suprema Argentina frente al Legado de la Última Dictadura Militar: Reseña del Fallo "Simón"}

\author{
Mariano Fernández Valle*
}

\section{Introducción}

El día 14 de junio de 2005, en una decisión histórica, la Corte Suprema de Justicia de la Nación Argentina dictó sentencia en el caso "Simón" declaró la inconstitucionalidad de las Leyes 23.492 y 23.521, conocidas como leyes de "Punto Final" (PF, año 1986) y "Obediencia Debida" (OD, año 1987) respectivamente. Asimismo, ratificó la Ley 25.779 que en el año 2003 las había "anulado" y privado de todo efecto jurídico por contrariar principios constitucionales y diferentes obligaciones asumidas por el país en el marco internacional. Como se explicará, las leyes de PF y OD, durante su vigencia, impidieron el procesamiento y castigo de los responsables de la comisión de crímenes aberrantes en la última dictadura militar (1976-1983).

Esta reseña presentará brevemente los antecedentes del caso "Simón" y analizará aquellos argumentos de Derecho Internacional de los Derechos Humanos que determinaron la decisión adoptada en él.

\section{Las Leyes de Punto Final y Obediencia Debida}

\section{II.a. Motivación política y contenido}

Interpretadas a su mejor luz, estas leyes tuvieron básicamente dos objetivos: por un lado, evitar el deterioro de la incipiente democracia argentina (reinstaurada en el año 1983), amenazada por un importante sector de las Fuerzas Armadas; por otro, pacificar al país y, principalmente, a los diferentes sectores sociales y políticos enfrentados a partir de la caída del gobierno de facto.

En resumidas cuentas, la Ley 23.492 ordenaba la extinción de las acciones penales contra integrantes de las Fuerzas Armadas, de seguridad, o de grupos terroristas, si no hubieran sido ya citados a indagatoria o no lo fueran dentro de los 60 días contados a partir de la promulgación de la ley. Por su parte, la Ley 23.521 presumía, sin admitir prueba en contrario, que quienes a la fecha de comisión del hecho se desempeñaban como oficiales jefes, oficiales subalternos, suboficiales y personal de tropa de las fuerzas armadas, de seguridad, policiales y penitenciarias, no eran punibles por los delitos cometidos entre el 24 de marzo de 1976 y el 26 de septiembre de 1983 por haber obrado en virtud de obediencia debida. La misma presunción se aplicaba a otros funcionarios si no se resolvía judicialmente, antes de los treinta días de promulgada la ley, que habían

\footnotetext{
* Abogado, profesor de Derecho

Constitucional

Universidad de Buenos Aires y Universidad de Palermo, Argentina; asesor de la Honorable Cámara de Diputados de la Nación

Argentina; coordinador de proyectos del Centro de Implementación de Políticas Públicas para la Equidad y el Crecimiento (CIPPEC).

1 "Simón, Julio Héctor y otros s/ privación ilegítima de la libertad, etc., causa $17.768^{\prime \prime}$.
}

Este comentario, junto con el documento principal a que se refiere, están disponibles en www.anuariocdh.uchile.cl 
2 Caso "Ramón Juan Alberto Camps y otros" (310:1162), y posteriores $(311: 80$ 312:111; etcétera).

3 Caso "Camps", op. Cit., considerandos Nos 33 y 34. tenido capacidad decisoria o que habían participado en la elaboración de órdenes. Tanto la ley de PF como de OD excluían de su ámbito de aplicación a determinados delitos (ej: sustracción y ocultamiento de menores).

II.b. Su primer análisis de constitucionalidad: convalidación por parte de la Corte Suprema de Justicia (año 1987)

Debe destacarse que la Corte Suprema de Justicia, muchos años antes del caso "Simón", tuvo la oportunidad de pronunciarse sobre la validez de ambas leyes, ratificando su constitucionalidad. Así, en el caso "Camps" 2 se entendió que la Ley 23.521 no puede interpretarse "con olvido de la particular coyuntura política que la motiva ni con indiferencia por los efectos que podría desencadenar su invalidación por este Tribunal", y que mediante la ley impugnada "los Poderes Ejecutivo y Legislativo han decidido, ante el grave conflicto de intereses que la sociedad argentina afronta en torno a este tema, conservar la paz social encauzando la voluntad popular en medidas que clausuren los enfrentamientos, en procura de alcanzar como meta indispensable la unión de los argentinos" 3 .

\section{II.c. Su derogación y posterior anulación}

Entre idas y vueltas, el 26 de marzo del año 1998 el Congreso Nacional derogó ambas leyes mediante la Ley 24.952, lo que constituyó más que nada un acto simbólico en virtud de que la derogación sólo operaba para el futuro y por ello no afectaba de ningún modo la situación legal de los beneficiarios del punto final y la obediencia debida.

Sin embargo, la muerte definitiva de estas leyes la determinó la Ley 25.779, cuyo artículo 1 las declaró "insanablemente nulas", pretendiendo de esta forma restarles todo efecto jurídico y eludir así las restricciones que el principio de ley penal más benigna imponía en favor de los perpetradores.

\section{El fallo "Simón"}

\section{III.a. Los hechos}

La decisión que ordenaba el procesamiento con prisión preventiva de Julio Héctor Simón Ilegó a la Corte Suprema de Justicia proveniente de la Sala II de la Cámara Nacional de Apelaciones en lo Criminal y Correccional Federal de la Ciudad de Buenos Aires.

Se imputaba al entonces suboficial de la Policía Federal Argentina el secuestro de José Poblete, su esposa Gertrudis Hlaczik, y la hija de ambos, Claudia Poblete, el día 27 de noviembre de 1978. Todos ellos habrían sido llevados a un centro clandestino de detención, donde el matrimonio habría sido torturado por Simón y luego trasladado sin que se conozca hasta el momento su paradero.

Como se verá a lo largo de este escrito, la cuestión encerraba diversos planteos de constitucionalidad. La defensa de los imputados apeló a la 
autoridad de las leyes de PF y OD, sostuvo que se había extinguido la acción penal contra sus beneficiarios y cuestionó la constitucionalidad de la norma que las anuló. Por su parte, los acusadores plantearon parte de su estrategia en la inconstitucionalidad de dichas leyes y en la validez de la norma anulatoria. En este escenario, la Corte tuvo que abocarse al análisis de todo el marco legal citado.

\section{III. b. Fundamentos}

Si bien la mayoría de los jueces declaró la inconstitucionalidad de las leyes de PF y $\mathrm{OD}^{4}$ y la constitucionalidad de la ley anulatoria ${ }^{5}$, no todos lo hicieron sobre la base de los mismos argumentos. Debe resaltarse que cada uno de los ministros de la Corte Suprema redactó su propio voto. Este hecho admite varias lecturas: refleja la complejidad del asunto tratado y, a su vez, revela la falta de diálogo existente en el tribunal, en parte, motivada por la incorporación reciente de nuevos magistrados. Lo cierto es que esta situación dificulta la posibilidad de extraer una doctrina mayoritaria de la sentencia. No existe la doctrina de la Corte en materia de inconstitucionalidad de las leyes de PF y OD o en lo relativo a la constitucionalidad de la ley anulatoria del Congreso Nacional, sino diferentes doctrinas propias de cada uno de los votos, en alguna medida divergentes. De todas formas, dentro de un diseño institucional donde las sentencias de los jueces sólo tienen efectos frente al caso concreto ${ }^{6}$, es esperable que la Corte sea nuevamente Ilamada a tratar causas similares y delimite mejor los alcances de su jurisprudencia.

\section{III.b. 1. La progresiva evolución del sistema internacional e interamericano de protección de los Derechos Humanos}

El fallo se fundó principalmente en la normativa internacional e interamericana de Derechos Humanos, y en principios generales de Derecho Internacional Público. Sin excepción, los jueces hicieron uso de disposiciones de la Convención Americana sobre Derechos Humanos (CADH), el Pacto Internacional de Derechos Civiles y Políticos (PIDCP), y la Convención Interamericana sobre la Desaparición Forzada de Personas, entre otras, así como de las decisiones emanadas de los órganos supranacionales contralores de estos instrumentos.

Quien en forma más explícita apeló al régimen supranacional para fundar su voto fue el juez preopinante Petracchi. Él se encontraba en una posición incómoda, considerando que en el pasado (causa "Camps") había convalidado las leyes que en este fallo invalidó. Este cambio, en palabras del propio Petracchi, respondió a la evolución y progresividad del Derecho Internacional de los Derechos Humanos y de las decisiones de sus órganos de vigilancia, que indubitablemente ya no autorizan al Estado "a tomar decisiones cuya consecuencia sea la renuncia a la persecución penal de delitos de lesa humanidad, en pos de una convivencia social pacífica apoyada en el olvido de hechos de esa naturaleza" (Considerando $N^{\circ} 14$ ). El voto analizado deja en evidencia las fuertes restricciones que el marco general de respeto y garantía de los Derechos Humanos impone a los Estados. Con apoyo en el Informe 28/92 de la Comisión
4 Votaron por la inconstitucionalidad los jueces Petracchi, Boggiano, Maqueda, Zaffaroni, Lorenzetti, Argibay y Highton. En disidencia el juez Fayt. El juez Belluscio se abstuvo.

5 Se pronunciaron expresamente sobre la validez de la norma anulatoria los jueces Petracchi, Maqueda, Zaffaroni, Lorenzetti y Highton.

6 En Argentina el control de constitucionalidad es judicial, difuso (cualquier juez puede declarar la inconstitucionalidad de una norma), se ejerce frente a casos concretos y con efecto inter partes. 
$7 \mathrm{CIDH}$, "Consuelo Herrera c. Argentina", Informe $\mathrm{N}^{\circ} 28,2$ de octubre de 1992.

8 Corte IDH, Caso Barrios Altos (Chumbipuma y otros c. Perú), Serie C, $N^{\circ} 75,14$ de marzo de 2001.

9 Corte IDH, Caso Velázquez Rodríguez, Serie C, $N^{\circ} 4,29$ de julio de 1988.

10 Observaciones finales sobre el informe de Argentina, adoptadas en su sesión $\mathrm{N}^{\circ} 53$, 5 de abril de 1995 .

${ }^{11}$ Los jueces intervinientes consideraron que las leyes de PF y OD operaron como verdaderas amnistías.
Interamericana de Derechos Humanos $(\mathrm{CIDH})$ que estableció que las leyes de PF y OD eran violatorias de los artículos 1, 8, y 25 de la $\mathrm{CADH}^{7}$, en los casos "Barrios Altos" ${ }^{8}$ y "Velásquez Rodríguez" ${ }^{9}$ de la Corte Interamericana de Derechos Humanos (Corte IDH); y en las observaciones finales sobre Argentina del Comité de Derechos Humanos de la ONU ${ }^{10}$, el juez Petracchi declaró la violación del deber de garantía por parte del Estado Nacional en virtud de que no creó las condiciones legales necesarias para la efectiva protección de los Derechos Humanos en su territorio. Entendió que el Estado incumplió su deber de proteger el derecho de acceso a la justicia de las víctimas y que la amnistía ${ }^{11}$, que antaño constituía una amplia facultad política de los gobiernos, actualmente no puede impedir la investigación y sanción de delitos como los imputados a Simón. Petracchi fundó su giro respecto de lo decidido en el caso "Camps", apelando principalmente a la labor de los órganos de control en la precisión del contenido de obligaciones internacionales que al momento de su anterior pronunciamiento él consideraba difusas e indeterminadas.

También la jueza Highton de Nolasco destacó la responsabilidad internacional que pesaba sobre el Estado argentino a raíz del dictado de las leyes de PF y OD. Sostuvo: "El Congreso Nacional no se encontraba habilitado para dictar las Leyes 23.521 y 23.492; y al hacerlo ha vulnerado no sólo principios constitucionales, sino también los tratados internacionales de derechos humanos, generando un sistema de impunidad con relación a delitos considerados como crímenes de lesa humanidad, del que se deriva la posibilidad cierta y concreta de generar responsabilidad internacional para el Estado argentino" (Considerando № 18).

Sin embargo, el contrapunto de las afirmaciones precedentes fue claramente expresado por el juez Fayt. En lo que constituyó la única disidencia en la causa, el magistrado decidió mantener la misma posición que sostuvo en el caso "Camps". Más allá de la resolución final, debe decirse que el exhaustivo análisis argumentativo del juez obliga a meditar seriamente sobre la tensa relación existente entre el avance progresivo del Derecho Internacional de los Derechos Humanos y el margen de discrecionalidad política de los Estados. Destacó que las decisiones de organismos supranacionales son necesarias para garantizar el pleno respeto de los derechos, pero a la vez imponen una cierta visión en desmedro de la construcción de cada una de las comunidades políticas. Fayt sostuvo que los tratados deben ajustarse y guardar conformidad con los principios de derecho público establecidos en la Constitución argentina, y que es indudable que nuestros constituyentes han consagrado desde antiguo un propio "margen nacional de apreciación" delimitado por esos principios de derecho público. Por ello, continúa, es inaceptable en nuestro sistema sostener la primacía del derecho internacional frente a la propia Constitución Nacional (Considerando $\mathrm{N}^{\circ} 55$ ).

Es evidente que los ministros Petracchi y Fayt respondieron al avance del Derecho Internacional de los Derechos Humanos de formas opuestas. Mientras que el primero reveló una sumisión absoluta a la doctrina de 
las entidades supranacionales de control ${ }^{12}$, el segundo dejó a salvo cierto margen de interpretación en manos de los Estados y sostuvo la superioridad de las decisiones de sus poderes constituyentes frente a obligaciones internacionales que las contraríen. Lo cierto es que esta dicotomía tampoco es nueva en nuestra historia judicial. La Corte Suprema siempre se ha comportado en forma pendular con relación al análisis de la jerarquía entre el derecho internacional y el derecho constitucional argentino, y en lo relativo al grado de obligatoriedad que las decisiones de las entidades supranacionales tienen para los tribunales locales ${ }^{13}$.

\section{III.b.2. El precedente Barrios Altos y su aplicabilidad al presente caso}

Todos los jueces que conformaron la mayoría apelaron a la doctrina sentada en el precedente de la Corte IDH establecido en el caso peruano "Barrios Altos" y sostuvieron su aplicación a la causa analizada, en virtud de las analogías existentes. Dicha sentencia, como señala Petracchi, establece indudablemente "la inadmisibilidad de las disposiciones de amnistía y prescripción, así como el establecimiento de excluyentes de responsabilidad que tiendan a impedir la investigación y sanción de los responsables de violaciones graves de los derechos humanos" (Considerando $\left.N^{\circ} 30\right)$. A su vez, nuestro máximo tribunal señaló que "Barrios Altos" no constituye un fallo aislado, sino que forma parte de una sostenida línea jurisprudencial del órgano interamericano en el mismo sentido.

Si bien existen diferencias fácticas entre el caso peruano y el argentino, la mayoría del caso "Simón" no las consideró relevantes a los efectos de aplicar la doctrina de la Corte IDH. Sólo la disidencia de Fayt se apartó de dicha apreciación y resaltó que el carácter democrático de las leyes de PF y OD les da una legitimidad que no poseen las leyes peruanas de autoaministía que impidieron la investigación de los hechos y la sanción de los responsables (Considerandos $\left.N^{o s} 79,80\right)^{14}$. Sin embargo, debe decirse que Fayt marca una diferencia relevante, pero en absoluto determinante. Es cierto que el origen democrático de una norma le otorga a ella una validez prima facie que no posee una norma de facto o emanada de un período autoritario, pero aún así esa presunción de validez puede caer cuando el contenido de la norma viola Derechos Humanos o mínimos estándares morales ${ }^{15}$. El origen de una norma ofrece presunciones relevantes, pero no hipoteca las posibilidades de realizar un adecuado análisis sustantivo.

\section{III.b.3. Derecho consuetudinario internacional y lus Cogens}

En la causa "Simón", la Corte Suprema retomó el criterio que había expuesto en el caso "Arancibia Clavel"16, relativo a la imposibilidad, derivada del derecho consuetudinario internacional, de extinguir la acción penal para la persecución de delitos de lesa humanidad. Los jueces Boggiano, Maqueda, Zaffaroni, Highton de Nolasco y Lorenzetti aplicaron dicho precedente y resaltaron que, aun en ausencia de norma escrita que lo disponga, estos delitos son imprescriptibles y no pueden ser amnistiados ${ }^{17}$.
12 Opción cuyo análisis excede los objetivos de este trabajo, pero que también puede resultar problemática.

13 En los casos "Ekmedjian c. Sofovich" (Fallos 315:1492), "Giroldi" (Fallos 318:514), la Corte reveló un fuerte respeto a las decisiones de la $\mathrm{CIDH}$ y de la Corte IDH, destacando la obligatoriedad de su doctrina en lo relativo a la interpretación de las cláusulas de la CADH. Tiempo después, en el fallo "Feliccetti" (Fallos 323:4130), la Corte afirmó que estas decisiones sólo ofrecen pautas de interpretación valiosas pero no determinantes para los tribunales locales.

14 Asimismo, señala el juez que mientras que las leyes peruanas crearon un sistema de impunidad absoluta, las leyes argentinas no lo hicieron.

(Considerandos $\mathrm{N}^{\text {os }} 81,82,83$ ).

15 Nino, Carlos S., "La validez de las normas de facto", en la

"Validez del Derecho", Ed. Astrea, Bs. As., 1985.

16 CSJN, "Arancibia Clavel, Enrique Lautaro s/ homicidio calificado y asociación ilícita y otros; causa $\mathrm{N}^{\circ} 259^{\prime \prime}$.

17 Moreno, Fernando R. “¿Estamos abandonando cada vez más el principio de legalidad?", Sup. Penal, Bs. As., mes de julio de 2005. 
${ }^{18}$ Es importante aclarar que la mayoría de las afirmaciones de la jueza Argibay se supeditan a que los delitos que se imputan a Simón sean considerados de "lesa humanidad". Como ella indica, esta clasificación todavía puede ser refutada dado el estado del proceso. Sin embargo, continúa, será también la Corte Suprema quien revise la clasificación cuando exista sentencia definitiva (Considerando $\left.\mathrm{N}^{\circ} 15\right)$.

${ }^{19}$ CSJN, Fallos 287.76.
El ministro Boggiano, quien fundamenta su voto principalmente en argumentos de Derecho Internacional Público, destacó que estos imperativos se encontraban plenamente vigentes al momento de la promulgación de las leyes de amnistía, con independencia de su recepción por el derecho positivo (Considerando $\mathrm{N}^{\circ} 42$ ). Con esta afirmación el juez rechaza una de las principales defensas de los imputados, fundada en el principio de legalidad y en la irretroactividad de la ley penal. Los acusados sostenían que, al momento de ser amnistiados estos delitos, no se encontraba vigente en Argentina la Convención sobre la Imprescriptibilidad de Crímenes de Guerra y de los Crímenes de Lesa Humanidad y la Convención Interamericana sobre la Desaparición Forzada de Personas. Asimismo, alegaban que los delitos de lesa humanidad, como tales, no se encontraban tipificados en el ordenamiento local.

Frente a esos argumentos, los jueces respondieron que dichas convenciones no hicieron más que ratificar principios que ya regían por formar parte del derecho consuetudinario. A su vez y a mayor abundamiento, tanto el juez Boggiano como la jueza Argibay ${ }^{18}$ destacaron que la misma Convención sobre Imprescriptibilidad autoriza su aplicación retroactiva. Dice Boggiano: "Ante el conflicto entre el principio de irretroactividad que favorecía al autor del delito contra el ius gentium y el principio de retroactividad aparente de los textos convencionales sobre imprescriptibilidad, debe prevalecer este último, pues es inherente a las normas imperativas de ius cogens" (Considerando $\mathrm{N}^{\circ} 43$ ).

Además, la jueza Argibay consideró que la posibilidad de aplicar dicha Convención con independencia de la fecha de comisión de los hechos no viola el principio de legalidad, ya que la prescripción de la acción penal no forma parte de éste (Considerando $N^{0} 16$ ). En este punto la jueza se diferenció del resto de sus colegas y del precedente sentado por la Corte en el fallo Mirás ${ }^{19}$. Mientras todos ellos consideraron que en términos generales la prescripción es parte del principio de legalidad, pero que frente a delitos de lesa humanidad no debe contemplarse, la jueza sostuvo que directamente la prescripción no forma parte de dicho principio.

Debe decirse que el juez Boggiano fue muy cuidadoso en limitar los alcances de su decisión a los crímenes de lesa humanidad, dejando abierta la puerta a la validez de las leyes de PF y OD respecto de otro tipo de delitos. Esto es de radical importancia, ya que los efectos de las sentencias de los tribunales son para las partes y no generales, razón por la cual nada obsta a que este juez defienda la validez de las amnistías frente a delitos que no sean de lesa humanidad en casos que lleguen a su conocimiento. Es interesante remarcar cómo esta interpretación se diferencia claramente de aquella que movió al Congreso Nacional a dictar la Ley anulatoria 25.779. Para el juez existe un marco de aplicación de las leyes de PF y OD por fuera de los delitos de lesa humanidad. No obstante, el Congreso optó por retirarlas del sistema jurídico y privarlas de efectos frente a cualquier caso. 
Respecto de la supuesta violación del principio de legalidad por la aplicación retroactiva de tipos penales, el juez Maqueda agregó que la desaparición forzada de personas no sólo configuraba un crimen de lesa humanidad para la ley internacional, sino que dicha conducta se encontraba también tipificada en el orden interno como delito de privación ilegítima de la libertad, lo que implica preservar el principio de legalidad, cuyo fin es que cualquiera que vaya a cometer un acto ilegal esté advertido con anterioridad que su conducta constituye delito y conlleva una pena (Considerandos $\mathrm{N}^{\text {os }} 83,84,85$ ). De esta forma, el juez no sólo apeló a la ley y costumbre internacionales, a los principios de lus Cogens, y al derecho de gentes ${ }^{20}$, sino que también destacó que el ordenamiento interno ya tipificaba este tipo de delitos, aun sin denominarlos con la nomenclatura internacional.

\section{III.b.4. Los derechos de las víctimas}

Si bien la existencia de un supuesto derecho de las víctimas al castigo de los perpetradores se vislumbra en la mayoría de los votos y se deriva de la aplicación de los casos "Velásquez Rodríguez" y "Barrios Altos", el juez Maqueda lo explicita y afirma que las Leyes 23.492 y 23.521 desconocen todo rol a las víctimas del terrorismo de Estado y a sus familiares para acudir a los tribunales a solicitar el esclarecimiento y la sanción penal de los responsables (Considerando $\mathrm{N}^{\circ} 29$ ).

En frontal oposición, la disidencia del juez Fayt ofrece algunas señales de alerta que obligan a una discusión más profunda sobre el punto. Sostiene el juez que "el derecho de la víctima a obtener la condena de una persona en concreto, de ninguna manera se compadece con la visión del castigo en un Estado de Derecho" (Considerando № 83).

Es de lamentar que no exista en el fallo un análisis exhaustivo del alcance de este derecho ni de los problemas que puede traer aparejada su exigencia en Estados con justificaciones no retributivas de la pena (Argentina, por ejemplo) ${ }^{21}$. Aun así, las críticas que señala Fayt son de cuidado y pueden extenderse también a la línea jurisprudencial de la Corte IDH, que a mi criterio se encuentra peligrosamente volcada hacia un reconocimiento cada vez más amplio del derecho a obtener una sanción penal como forma de reparación para las víctimas ${ }^{22}$.

\section{Ley 25.779: nulidad por inconstitucionalidad de las leyes de Punto Final y Obediencia Debida}

Es imposible cerrar este comentario sin hacer referencia al análisis de la ley anulatoria, de trascendental importancia en la causa decidida. Como se dijo, la derogación de las leyes no permitió que se impulsaran los procesos judiciales pendientes y, por ende, no liberó a la República Argentina de su responsabilidad internacional por violación del deber de respeto y garantía de los Derechos Humanos. Por ello, el Congreso Nacional intentó mediante la Ley 25.779 ofrecer una solución general que prive de todo efecto jurídico a las normas de PF y OD, anulándolas por inconstitucionales.
20 Incorporado a la Constitución argentina en el artículo 118.

21 El artículo 18 de la Constitución argentina sostiene que "...las cárceles de la Nación serán sanas y limpias, no para el castigo de los reos detenidos en ellas sino para su seguridad...".

22 Ver Pastor, Daniel R. "La deriva neopunitivista de organismos y activistas como causa del desprestigio actual de los derechos humanos". Separata Nueva Doctrina Penal, Tomo A, Bs. As., 2005. 
${ }^{23}$ Ley 23.040. La validez de dicha nulidad fue ratificada por la Corte Suprema en la "Causa originariamente instruida por el Consejo Supremo de las Fuerzas Armadas en cumplimiento del decreto 158/83", del 30 de diciembre de 1986.

${ }^{24}$ Fundamentos de la ley anulatoria 23.040 .
No abundan en nuestra historia ejemplos de este tipo. Sólo existe un importante precedente del año 1983, relativo a la anulación por parte del Congreso Nacional de la Ley de facto $22.924^{23}$. Dicha ley había sido dictada por el gobierno militar y preveía una amplia amnistía para quienes habían formado parte de él. Al anularla, se describían sus vicios de la siguiente manera: "En primer lugar, al beneficiar principalmente a quienes estaban directamente representados por el gobierno que la dictó, la ley concede una verdadera autoamnistía que constituye un privilegio repugnante al principio de igualdad ante la ley (...) En segundo lugar, la ley en cuestión se hace pasible de la nulidad insanable que el artículo 29 de la Constitución Nacional imputa (...) a todo acto que implique la concesión de la suma del poder público (...) En tercer lugar, la descalificación de la aberrante doctrina de los gobiernos de facto implica conceder a las normas de ese origen sólo una validez precaria, la que queda precluida cuando, como en este caso, el contenido de la norma es claramente inicuo (...) Al ser esta ley insanablemente nula -como expresamente se lo declara-, ella no tiene efecto jurídico alguno, y en especial es completamente inaplicable el principio de la ley más benigna...." 24 .

Es claro que estos argumentos no pueden traspolarse directamente al análisis de la Ley 25.779. La ley 23.040 declaraba nula a una ley de facto, mientras que la segunda priva de efectos jurídicos a dos normas sancionadas por un gobierno democrático (PF y OD). Sólo cinco de los jueces se pronunciaron en el fallo "Simón" ratificando expresamente la constitucionalidad de la Ley 25.779, con argumentos nuevamente dispares.

El juez Maqueda validó la Ley 25.779 y recalcó que es evidente que no sólo el Poder Judicial revisa la constitucionalidad de una norma, sino que también los poderes políticos deben hacerlo de forma previa a su entrada en vigencia. Ahora bien, frente a ello, fácilmente podría argumentarse que este caso es diferente, ya que se analiza si el Poder Legislativo obró dentro de sus facultades cuando declaró la nulidad de normas que estaban plenamente vigentes y que produjeron efectos jurídicos.

Zaffaroni y Lorenzetti en principio defendieron el monopolio judicial del control de constitucionalidad y rechazaron los argumentos sobre los cuales se justificó en el Congreso la ley anulatoria. Ambos jueces analizaron pormenorizadamente el debate parlamentario y descartaron uno a uno los argumentos que allí se ofrecieron. Así, sostuvieron que no es posible fundar la nulidad de una ley sobre la base de razones tales como el análisis de su conveniencia, el grado de libertad existente al momento de promulgarla, o la necesidad de crear un orden jurídico no contradictorio. Dijo Zaffaroni: "Es verdad que el Congreso de la Nación suele sancionar leyes presionado por las circunstancias con mucha frecuencia y eso es materia corriente en la política de cualquier Estado. Abrir la puerta de futuras nulidades invocando el estado de necesidad o la coacción en cada uno de esos casos importa sembrar una inseguridad 
jurídica formidable" (Considerando N²3). Y continúa sosteniendo que si "la contradicción entre normas vigentes facultase para la anulación de leyes, no sería difícil anular la mayoría (...) El legislador puede incurrir en contradicciones (...) pero es tarea de los jueces reducirlas..." (Considerando $\mathrm{N}^{\circ}$ 28). Sin embargo, aun habiendo rechazado los argumentos previamente citados, tanto Zaffaroni como Lorenzetti concluyeron que podría admitirse por vía de excepción la posibilidad de que el Congreso prive de todo efecto jurídico a una norma cuando existe un claro mandato internacional que impone la unidad de criterio en todo el territorio, y están en juego el ejercicio de la soberanía, la esencia de la Constitución y la dignidad de la Nación. Bajo la comprensión de que este caso presentaba dichas características, ambos jueces ratificaron la norma 25.779 .

Por su parte, la jueza Highton recordó que la ley anulatoria pretendió subsanar infracciones y cumplir de manera adecuada las obligaciones asumidas mediante tratados internacionales de Derechos Humanos, eliminando los impedimentos normativos para la investigación y la punición de delitos aberrantes. Entendiendo que este era uno de los efectos de la aplicación del caso "Barrios Altos", la jueza consagró la validez constitucional de la Ley $25.779^{25}$.

Finalmente, el juez Petracchi también sostuvo la validez de la norma anulatoria, pero con un argumento exclusivamente pragmático. Aunque defendió el monopolio judicial de esta facultad, resolvió que constituiría un formalismo vacío no reconocer la validez de una norma que resuelve la situación de las leyes de PF y OD de la misma forma en que, a su criterio, deben hacerlo los jueces (Considerando $\mathrm{N}^{0} 34$ ).

Si bien cada uno de los votos posee sus particularidades, las apreciaciones vertidas en los párrafos precedentes permiten extraer las siguientes conclusiones y observaciones: Es claro que la mayoría de los magistrados sostuvo que en principio sólo el Poder Judicial tiene la facultad de anular una norma vigente por inconstitucional, más allá de que en este caso concreto se haya reconocido dicha facultad, por vía de excepción, al Poder Legislativo. Leído en clave política, ninguno de los jueces está dispuesto a entregar fácilmente el enorme poder que representa tener la última palabra en cuanto a la constitucionalidad de una norma. Sin embargo, cabe contraargumentar y decir que el control de constitucionalidad en Argentina es judicial porque los mismos jueces se lo adjudicaron. En ausencia de una referencia explícita en la Constitución, los magistrados de los célebres casos "Sojo" 26 y "Municipalidad de la Capital c. Elortondo" 27 se adjudicaron este poder, emulando lo decidido por la Corte norteamericana en "Mardbury vs. Madison".

Asimismo, también es importante recalcar que no es posible sostener livianamente que el Congreso invade funciones judiciales cuando anula una norma por inconstitucional. Aunque la Corte Suprema haya abusado de este argumento, no puede determinarse la existencia de una violación de poderes, si primero no se explicita cuál es la visión de la democracia que se defiende. La decisión democrática, luego de la deliberación y la
25 El voto de la jueza Highton llama la atención sobre la falta de claridad que reina a la hora de determinar a cuáles mecanismos deben o pueden apelar los Estados a los efectos de liberarse de responsabilidad internacional.

26 CSJN, Fallos 32:135.

27 CSJN, Fallos 33:133. 
28 Nino, Carlos Santiago. "La Constitución de la democracia deliberativa", Ed. Gedisa, Barcelona, 2003, c.7; Gargarella, Roberto, "La justicia frente al gobierno", Ed Ariel, Barcelona, 1996, p. 58. participación de los potenciales afectados, tiene un valor epistémico que jamás puede tener una sentencia. No debe perderse de vista que los jueces están alejados de la voluntad popular, no tienen legitimidad democrática y se manejan con el enorme margen de discrecionalidad que los textos constitucionales permiten, sin mayores controles políticos y ciudadanos ${ }^{28}$.

Para concluir, debe ponerse al descubierto que la misma inseguridad jurídica que temen jueces como Zaffaroni a la hora de reconocer al Congreso la facultad para anular una norma tiene lugar cuando son ellos mismos los que conservan el monopolio de este poder. Principalmente en sistemas como el argentino, donde el control judicial es difuso y no existe obligación legal de seguir los precedentes. 